$\begin{array}{ll}\text { KREATIF } & \text { Pamulang ISSN : 2339-0689, E-ISSN : 2406-8616 } \\ \text { Jurnal Ilmiah } & \text { J. KREATIF, Vol. 7, No. 2, Desember } 2019 \text { (Halaman 84-91) } \\ \text { Prodi Manaiemen Universitas Pamulang } & \text { Tersedia Online di : http://openjournal.unpam.ac.id/index.php/kreatif }\end{array}$

\title{
PENGARUH PRO MOSI TERHADAP KEPUTUSAN MENDAFTAR MURID MEMILIH SMK CAHAYA PRIMA
}

\author{
${ }^{1}$ Suharni Rahayu, ${ }^{2}$ Andreas Ardi Wijaya \\ Program Studi Manajemen \\ ${ }^{1}$ Dosen Universitas Pamulang \\ ${ }^{2}$ Alumni Universitas Pamulang \\ dosen00964@unpam.ac.id
}

\begin{abstract}
ABSTRAK
Penelitian ini bertujuan untuk mengetahui promosi yang dilakukan di SMK Cahaya Prima. Untuk men getahui keputusan mendaftar murid memilih SMK Cahaya Prima. Untuk mengetahui pengaruh promosi terhadap keputusan mendaftar murid memilih SMK Cahaya Prima.

Penelitian ini bersifat asosiatif kuantitatif dengan pendekatan kuantitatif Populasi penelitian ini sebanyak 90 siswa, sampel yang digunakan dalam penelitian ini sebanyak 90 responden. Teknik pengumpulan data dengan cara kuesioner dan teknik dengan uji validitas, uji reliabilitas, uji regresi linier sederhana, uji koefisiensi korelasi, uji koefisien determinasi dan uji hipotesis uji t.

Promosi di SMK Cahaya Prima dikatakan Sedang. Hal itu dapat dilihat dari nilai rata - rata variabel promosi yaitu sebesar 3,31 ada pada skala interval 2,61-3,40 dengan kategori Sedang. Keputusan Pembelian Mendaftar di SMK Cahaya Prima dikatakan tinggi. Hal itu dapat dilihat dari nilai rata -rata variabel Keputusan Pembelian Mendaftar yaitu sebesar 3,54 ada pada skala interval 3,41 4,20 dengan katagori Tinggi. Terdapat pengaruh positif lemah rendah dan signifikan antara Promosi dan Keputusan Pembelian / Mendaftar di SMK Cahaya Prima. Hal ini dapat dilihat dari nilai koefisien regresi linier sederhana $\mathrm{Y}=29,843$ $+0,429 X$. Nilai koefisien korelasi $r=0,272$. Nilai koefisien determinasi $R=7,4$ $\%$. Nilai t hitung $>$ t table $(2,650>1,987)$.
\end{abstract}

Kata Kunci : Promosi dan Keputusan Pembelian.

\section{ABSTRACT}

This study aims to determine the promotion carried out at SMK Prima Prima. To find out the decision to register students choose SMK Prima Prima. To determine the effect of promotion on the decision to register students choose SMK Prima Prima.

This research is a quantitative associative approach with a quantitative approach. The study population was 90 students, the sample used in this study was 90 respondents. Data collection techniques by means of questionnaires and techniques with validity test, reliability test, simple linear regression test, correlation coefficient test, coefficient of determination test and hypothesis test $t$ test.

Promotion at SMK Prima Prima is said to be Medium. It can be seen from the average value of the promotion variable that is equal to 3.31 on an interval scale of 2.61-3.40 with the Medium category. The Purchase Decision to Register 
at SMK Prima Prima is said to be high. It can be seen from the average value of the Registered Purchase Decision variable that is equal to 3.54 on an interval scale of $3.41-4.20$ with the High category. There is a low positive and significant positive influence between Promotion and Purchasing / Registering Decisions at SMK Cahaya Prima. This can be seen from the simple linear regression coefficient $Y=29.843+0.429 X$. Correlation coefficient value $r=0.272$. The coefficient of determination $R=7.4 \%$. $T$ value $>$ t table $(2,650>1,987)$.

Keywords: Promotion and Purchasing Decisions.

\section{PENDAHULUAN}

\section{A. Latar Belakang}

Di DKI Jakarta Barat, khususnya Kali Deres saat ini banyak sekali sekolah-sekolah yang menawarkan produknya serupa dengan SMK Cahaya Prima, yaitu pendidikan yang berbasis Komputer Jaringan, dengan slogannya adalah "Mencerdaskan Siswa Melalui Kemajuan Ilmu Teknologi". Di wilayah Kali Deres ada beberapa sekolah yang mempunyai pangsa pasar yang sama dengan SMK Cahaya Prima, diantaranya SMK Citra Utama, SMK Taman Sakti, SMK Yadika, SMK Negeri 53, SMK Al-Huda, SMK Putra Negara dan banyak sekolah serupa. Oleh karena itu, SMK Cahaya Prima perlu mengembangkan strategi promosinya untuk menarik siswa lulusan SMP di sekitar "Wilayah Kali Deres untuk bersekolah di SMK Cahaya Prima yang mempunyai kualitas yang cukup baik dibidangnya. Kegiatan promosi telah dilakukan SMK Cahaya Prima seperti pemasangan spanduk dan penyebaran brosur.

Target perolehan siswa pada SMK Cahaya Prima, dari tahun ke tahun target perolehan jumlah siswa tidak berubah yaitu sebanyak 100 siswa. Sedangkan pendaftar yang akan bersekolah dilihat dalam kurun waktu dua tahun terlihat fluktuatif dimana jumlah calon siswa SMK Cahaya Prima pada tahun pertama yang diterima sebanyak 68 siswa. Sebanyak 50 siswa mendapatkan informasi dari brosur yang telah disebar dan 18 siswa lainnya mendapatkan informasi dari spanduk yang telah dipasang. Pada tahun kedua mengalami penurunan siswa yang diterima sebanyak 25 siswa. Sebanyak 18 siswa mendapatkan informasi dari brosur dan 7 siswa lainnya mendapatkan informasi dari spanduk. Kegiatan promosi telah dilakukan SMK Cahaya Prima seperti pemasangan spanduk dan penyebaran brosur. Untuk dapat bersekolah di SMK Cahaya Prima para pendaftar atau siswa diwajibkan mengisi formulir, karena minimnya informasi akan sekolah yang pada awalnya informasi diperoleh dari para tenaga pendidik, pergantian tenaga didik, brosur yang belum efektif diterima masyarakat, minim nya pengetahuan sarana promosi. Hal ini menyebabkan penurunan jumlah siswa yang diterima pada tahun berikutnya. Pada tahun ke tiga sebanyak 90 siswa yang diterima. Sebanyak 75 siswa mendapatkan informasi dari brosur dan 15 siswa lainnya mendapatkan informasi dari spanduk. Untuk lebihjelasnya dapat dilihat pada gambar 1.1 yang menunjukan perbedaan yang cukup jauh antara target perolehan jumlah siswa dengan jumlah siswa yang diterima pada setiap tahunnya. 


\section{B. Perumusan Masalah}

1. Bagaimana promosi pada SMK Cahaya Prima?

2. Bagaimana keputusan siswa SMP untuk memilih SMK Cahaya Prima?

3. Seberapa besar pengaruh Promosi terhadap Keputusan siswa mendaftar di SMK Cahaya Prima?

\section{TINJAUAN PUSTAKA}

\section{A. Pemasaran}

Menurut Daryanto (2011:1) "Pemasaran adalah suatu proses sosial dan manajerial dimana individu dan kelompok mendpatkan keburukan dan keinginan mereka dengan menciptakan dan menawarkan dan bertukar sesuatu yang bernilai satu sama lain".

\section{B. Manajemen Pemasaran}

"Manajemen pemasaran adalah penganalisaan, pelaksanaan, dan pengawasan, program-program yang ditujukan untuk mengadakan pertukaran dengan pasar yang dituju dengan maksud untuk mencapai tujuan organisasi. Hal ini sangat tergantung pada penawaran organisasi dalam memenuhi kebutuhan dan keinginan pasar tersebut serta menentukan harga, mengadakan komunikasi, dan distribusi yang efektif untuk memberitahu, mendorong serta melayani pasar" Kolter dan Keller (2012:146).

\section{Bauaran Pemasaran}

Marketing mix atau bauran pemasaran harus selalu dapat menyesuaikan diri dengan lingkungan eksternal maupun internal. Faktor eksternal yaitu faktor diluar jangkauan perusahaan yang antara lain terdiri dari pesaing, teknologi, peraturan pemerintah, keadaan perekonomian, dan lingkungan sosial budaya. Sedangkan faktor internal adalah variabel- variabel yang terdapat dalam marketing mix yakni : Product (produk), Price (Harga), Place (Tempat), dan Promotion (Promosi), People (Orang), physical Evidence (Bukti fisik), dan Process (Proses).

\section{Promosi}

"Defmisi promosi adalah sarana dimana perusahaan berusaha untuk menginformasikan, membujuk dan mengingatkan konsumen baik secara langsung atau tidak langsung tentang produk dan merek yang mereka jual" (Kotler and Keller 2012:496). "Pengertian promosi ialah salah satu komponen prioritas dari kegiatan pemasaran yang memberitahukan kepada konsumen bahwa perusahaan meluncurkan produk baru yang menggoda konsumen untuk melakukan kegiatan pembelian" (Hermawan, 2013:38).

\section{E. Bauran Promosi}

Bauran promosi merupakan alat komnuikasi yang terdiri dari kombinasi alatalat promosi yang digunakan oleh perusahaan. Pada umumnya alat-alat promosi tersebut memiliki hubungan yang erat, sehingga diantaranya tidak dapat dipisahkan, karena bersifat Baling mendukung dan melengkapi.

\section{F. Keputusan Pembelian}

Keputusan pembelian dalam suatu bisnis merupakan hal yang ditunggutunggu oleh produsen. Keputusan untuk membeli suatu produk barang ataupunjasa timbul karena adanya dorongan emosional dari dalam diri maupun pengaruh dari orang lain. Menurut Kotler dan Armstrong 
(2012:157), "Consumer buyer behavior refers to the buying behavior of final consum - individuals and households that buy goets and services for personal consumption", pengertian tersebut dapat diartikan bahwa perilaku keputusan pembelian mengacu pada perilaku pembelian akhir dari konsumen, baik individual, maupun rwnah tangga yang membeli barang dan jasa untuk konsumsi pribadi.

\section{METODE PENELITIAN}

\section{A. Ruang Lingkup Penelitian}

Penelitian dilakukan pada SMK CAHAYA PRIMA yang beralamat di Jalan Prima No. 1 Kelurahan Tegal Alur, Kota Jakarta Barat, 11820.

\section{B. Metode Penentuan Populasi dan Sampel}

Berdasarkan pada tempat penelitian yang ditetapkan maka populasi yang dijadikan objek dalam penelitian ini adalah siswa yang telah mendaftar di SMK Cahaya Prima sebanyak 90 Siswa. Berdasarkan pada tempat penelitian yang telah ditetapkan, maka sampel yang dijadikan objek dalam penelitian ini adalah siswa yang telah mendaftar di SMK Cahaya Prima sebanyak 90 siswa

\section{Metode Analisis Data}

1. Pengujian Instrumen

Uji validitas dalam penelitian ini menggunakan Korelasi product moment yang diperoleh nilai $r$ hitung dan di bandingkan dengan nilai $r$ table yang telah di tentukan dalam penelitian ini. Setelah dilakukan uji validitas dan instrument yang dinyatakan valid maka di lakukan uji reliabilitas untuk memnguji kekonsitenan sebuah kuisioner degan membandingkan nila rca dengan $r$ table yang telah di tentukan dalam penelitian ini.

2. Analisis Regresi Linier Sederhana

Analisis Regresi Sederhana adalah sebuah metode pendekatan untuk pemodelan hubungan antara satu variabel dependen dan satu variabel independen. Dalam analisis regresi sederhana, hubungan antara variabel bersifat linier, dimana perubahan pada variabel $X$ akan diikuti oleh perubahan pada variabel Y secara tetap. Secara matematis model analisis regresi linier sederhana dapat digambarkan sebagai berikut:

$\mathbf{Y}=\mathbf{a}+\mathbf{b x}+\mathbf{e}$

$\mathrm{Y}$ adalah variabel dependen atau respon

a adalah intercept atau konstanta

$\mathrm{b}$ adalah koefisien regresi atau slope

e adalah residual atau error

3. Koefisien Korelasi

Pada bab ini akan dibahas analisis korelasi sederhana dengan metode Pearson atau sering disebut Product Moment Pearson. Nilai korelasi (r) berkisar antara 1 sampai -1 , nilai semakin mendekati 1 atau -1 berarti hubungan antara dua variabel semakin kuat, sebaliknya nilai mendekati 0 berarti hubungan antara dua variabel semakin lemah. Nilai positif menunjukkan hubungan searah (X naik maka $\mathrm{Y}$ naik) dan nilai negatif menunjukkan hubungan terbalik (X naik maka Y turun).

4. Koefisien Determinasi 
Koefisien determinasi $\left(\mathrm{R}^{2}\right)$ mengukur seberapa jauh kemampuan model yang dibentuk dalam menerangkan variasi variabel independen. Nilai koefisien determinasi $\left(\mathrm{R}^{2}\right)$ yaitu antara nol dan satu.

5. Uji Hipotesis

Uji signifikan terhadap hipotesis yang telah ditentukan dengan menggunakan uji t. Menurut Sugiyono (2014:243), rumus untuk menguji uji t sebagai berikut:

$$
t=\frac{r \sqrt{n-2}}{\sqrt{1-r^{2}}}
$$

Keterangan:

$\mathrm{t}=$ Nilai Uji $\mathrm{t}$

$\mathrm{r}=$ Koefisien korelasi

$r^{2}=$ Koefisien determinasi

$\mathrm{n}=$ Jumlah sampel

\section{HASILPENELITIAN}

\section{A. Hasil Uji Instrumen}

1. Uji Validitas

Tabel Uji Validitas

\begin{tabular}{|c|c|c|c|}
\hline \multicolumn{4}{|c|}{ Promosi } \\
\hline $\begin{array}{c}\text { No. } \\
\text { Kuisioner }\end{array}$ & $\begin{array}{c}\text { Koefisien } \\
\text { Korelasi }\end{array}$ & $\begin{array}{c}\text { R- } \\
\text { table }\end{array}$ & Keterangan* \\
\hline I & 0.414 & $* 0.300$ & Valid \\
\hline 2 & 0.509 & $* 0.300$ & Valid* \\
\hline 3 & 0.607 & $* 0.300$ & Valid* \\
\hline 4 & 0.651 & $* 0.300$ & Valid* \\
\hline 5 & 0.685 & $* 0.300$ & Valid* \\
\hline 6 & 0.579 & $* 0.300$ & Valid* \\
\hline \multicolumn{4}{|c|}{ Keputusan } \\
\hline 1 & 0.331 & $* 0.300$ & Valid \\
\hline 2 & 0.457 & $* 0.300$ & Valid* \\
\hline 3 & 0.575 & $* 0.300$ & Valid* \\
\hline 4 & 0.617 & $* 0.300$ & Valid* \\
\hline 5 & 0.403 & $* 0.300$ & Valid* \\
\hline 6 & 0.735 & $* 0.300$ & Valid* \\
\hline 7 & 0.697 & $* 0.300$ & Valid* \\
\hline 8 & 0.617 & $* 0.300$ & Valid* \\
\hline 9 & 0.725 & $* 0.300$ & Valid* \\
\hline 10 & 0.693 & $* 0.300$ & Valid* \\
\hline
\end{tabular}

2. Uji Relibilitas

Tabel Uji Relibalitas

\begin{tabular}{|l|l|l|l|l|}
\hline No & Variabel & Alpha Cronbacch & Syarat & Keterangan \\
\hline
\end{tabular}




\begin{tabular}{|c|c|c|c|c|}
1 & Promosi & 0.604 & 0.6 & Reliabel \\
\hline 2 & Keputusan Pembelian & 0.789 & 0.6 & Reliabel \\
\hline
\end{tabular}

\section{B. Hasil penelitian Dan Pembahasan}

1. Regresi Linier Sederhana

Tabel Cofficient ${ }^{\mathrm{s}}$

\begin{tabular}{|c|c|c|c|c|c|}
\hline \multirow[b]{2}{*}{ Model } & \multicolumn{2}{|c|}{$\begin{array}{c}\text { Unstandardized } \\
\text { Coefficients }\end{array}$} & \multirow{2}{*}{\begin{tabular}{|c|}
$\begin{array}{l}\text { Standardized } \\
\text { Coefficients }\end{array}$ \\
Beta
\end{tabular}} & \multirow[b]{2}{*}{$\mathrm{T}$} & \multirow[b]{2}{*}{ Sig. } \\
\hline & B & Std. Error & & & \\
\hline (Constant) & 29.843 & 3.630 & & 8.221 & .000 \\
\hline Promosi & .429 & .162 & .272 & 2.650 & .010 \\
\hline
\end{tabular}

a. Dependent Vanable: Kep. Pem

Berdasarkan tabel di atas diperoleh persamaan regresi berganda sebagai berikut : $\mathbf{Y}=\mathbf{2 9 , 8 4 3 + \mathbf { 0 , 4 2 9 } x}$

Dari persamaan tersebut Promosi mempunyai pengaruh yang positif terhadap keputusan mendaftar murid. Hubungan positif itu dapat dilihat nilai b yang bernilai positif. Hubungan positif tersebut menunjuke bahwa Promosi yang baik akan sejalan dengan perubahan keputusan mendaftar murid. Persamaan regresi tersebut mempunyai makna sebagai berikut:

a. Nilai Konstanta sebesar 29,843 menyatakan bahwa Jika promosi (x) tidak dipertimbangkan atau $(\mathrm{X}=0)$ maka keputusan mendaftaii $\mathrm{Y})$ bernilai hanya mencapai sebesar 0,429 .

b. Nilai koefisien regresi bemilai positif, hal ini menyatakan bahwa adanya hubungan yang positif antara promosi dengan keputusan mendaftar murid. Artinya peningkatan promosi akan meningkatkan keputusan mendaftar murid memilih SMK Cahaya Prima

2. Korelasi

Tabel Koefisien Korelasi

Model Summary

\begin{tabular}{|c|r|r|r|r|}
\hline Model & R & R Square & \multicolumn{1}{|c|}{$\begin{array}{c}\text { Adjusted R } \\
\text { Square }\end{array}$} & $\begin{array}{l}\text { Std. Error of } \\
\text { the Estimate }\end{array}$ \\
\hline & $.272^{\prime \prime}$ & -074 & -063 & 5.843 \\
\hline
\end{tabular}

a. Predictors: (Constant), Promosi

Berdasarkan hasil perhitungan pada tabel ditas diperoleh koefisien korelasinya adalah sebesar 0,272 dimana promosi (x) memiliki hubungan yang "lemah/rendah" terhadap keputusct pembelian (y) karena 0,272 berada diantara $0,20 \mathrm{~s} / \mathrm{d}$ 0,399.

3. Determinasi

Berdasarkan hasil perhitungan tabel korelasi maka analisis koefisien determinasi dapat diperoleh sebesar 0,074, maka dapat disimpulkan bahwa promosi (X) berpengaruh terhadap keputusan pembelian memilih murid (sebesar 7,4\% sedangkan sisanya sebesar 92,6\%, dipengaruhi oleh faktor lain yang tidak diteliti oleh penulis. 


\section{Hipotesis}

Pengaruh dari masing - masing variabel $\mathrm{x}$ (promosi) terhadap keputusan pembelian (y) dapat $\mathrm{d}$ ilihat dari arah tanda dan tingkat signifikan (probabilitas) dimana karena nilai signifikansi $<0,05$ atau pada $t$ tabel dengan nilai signifikansi 0,05. maka diperoleh $t$ tabel :

Pengaruh Promosi (x) terhadap Keputusan pembelian (y) dillihat pada table Coffcients Regresi Linear Sederhana dimana : Hasil uji parsial (uji t) antara promosi terhadap keputusan pembelian menunjukan nilai $t$ hitung > t tabel $(2,650>1,987)$ dan sig < $0,05(0,010<0,05)$ sehingga Ho ditolak dan Ha diterima yaitu "terdapat pengaruh promosi terhadap keputusan murid memilih SMK Cahaya Prima.

\section{PENUTUP}

\section{A. Kesimpulan}

1. Berdasarkan hasil penelitian promosi yang dilakukan oleh Sekolah SMK Cahaya Prima,dilihat Berdasarkan nilai rata - rata variabel promosi yaitu 3,31 berada di kategori skala (2,61 -3,40: Sedang) dimana tanggapan responden terhadap variabel Promosi memiliki kategori skala sedang atau cukup baik, dilihat dari skor tertinggi 4,02 yaitu pada indikator promosi penjualan sales promotion dimana pernyataan "Saya mendapatkan brosur dari Siswa Siswi Cahaya prima". Sehingga banyak responden yang memilih keputusan mendaftar di Sekolah Cahaya Prima karena brosur yang tepat sasaran.

2. Berdasarkan hasil penelitian keputusan pembelian yang dilakukan oleh siswa Sekolah SMK Cahaya Prima,dilihat Berdasarkan nilai rata-rata variabel keputusan pembelian yaitu 3,54 berada kategori skala $(3,41-4,20$ : Tinggi) djmana tanggapan responden terhadap variabel keputusan pembelian (y) memiliki kategori skala tinggi atau baik,dilihat dari skor tertinggi 4,22 yaitu pada indikator pengenalan masalah dimana dalam pernyataan "Saya ingin bersekolah dengan biaya yang terjangkau. Sehingga banyak responden yang memilih Sekolah Cahaya prima sebagai kebutuhan untuk mencari sekolah dengan biaya yang terjangkau.

3. Berdasarkan rurnusan masalah maka Promosi memiliki pengaruh yang positif dan signifikan terhadap keputusan pembelian dimana diperoleh nilai $\mathrm{t}$ hitung $>\mathrm{t}$ table $(2,650>1,987)$ dan sig $<0,05(0,010<0,05)$. Hasil persamaan regresi diperoleh $\mathrm{Y}=29,843+0,429 \mathrm{x}$ semakin tinggi promosi maka akan semakin meningkat keputusan pembelian. Demikian pula sebaliknya, jika promosi rendah maka keputusan pembelian juga akan menurun.

\section{B. Saran}

1. Pihak sekolah harus lebih meningkatkan promosi dari indikator penjualan personal dimana "Saya Bersekolah di SMK Cahaya Prima Karena ditawarkan Oleh Guru SMK Cahaya Prima". Karena diperoleh skor terendah 2,84. Maka dari itu sekolah harus meningkatkan kembali promosi dari segi penawaran yang dilakukan oleh guru. Walaupun beberapa guru panitia penerimaan siswa baru sudah menawarkan kepada calon siswa,diperlukan semua guru untuk dapat secara maksimal mempromosikan kepada calon siswa. 
2. Pihak sekolah harus lebih meningkatkan keputusan mendaftar siswa dari indikator Pencarian informasi dimana pada pernyataan "Saya mencari informasi dari spanduk mengenai SMK Cahaya Prima". Karena diperoleh skor terendah 3,56. Maka dari itu pihak sekolah harus meningkatkan kembali keputusan mendaftar siswa dari segi pemasangan spanduk yang tepat dan terlihat baik oleh caJon siswa sehingga tepat sasaran dan caJon siswa mendapatkan informasi dengan akurat.

3. Berdasarkan tingkat hubungan variabel, kedua variabel memiliki hubungan yang lemahlrendah, jadi sekolah harus lebih banyak meningkatkan promosi di berbagai aspek agar siswa bisa mengenal dan memilih SMK Cahaya Prima sebagai pilihan memilih sekolahnya.

\section{DAFTAR PUSTAKA}

Alma, Buchori, (2012), Manajemen Pemasaran \& Pemasaran Jasa, CV. Alfabeta, Bandung

Ghozali, Imam, (2012), Aplikasi Ana/isis Multivariate Dengan Program SPSS. Edisi 20, Badan Penerbit Universitas Diponegoro. Semarang.

G.R. Terry, (2010), Dasar-Dasar Manajemen, Bumi Aksara. Jakarta

Hasibuan, Malayu S.P, (2009), Manajemen Dasar, Pengertian, Dan Masalah. PT. Bumi Aksra, Jakarta

Hasibuan, Malayu S.P, (2012), Manajemen Dasar. PT. Bumi Aksra, Jakarta

Istijianto, (2009), Aplikasi Praktis Rise! Pemasaran, Gramedia Pustaka Utama, Jakarta.

Giyanto, (2008), Metedologi Penelitian Sistem Injormasi, CV. Andi Offset, Yogyakarta. Kotler dan Keller. (2012), Manaejemen Pemasaran, Edisi 12, Erlangga, Jakarta

Keller, Kevin Lane dan Garry Amstrong, (2012), Prinsip-Prinsip Pemasaran, Edisi 12, Jilid I, Erlangga Jakarta.

Santoso, Singgl, (2014), " Paduan Lengkap SPSS Versi 20 Edisi Revisi", Gramedia Pustaka Utama, Jakarta.

Sugiyono, (2010), Metode Penelitian Kuantitatif Kualitatif dan $R \& D$, Penerbit CV. A1fabeta, Bandung.

Sugiyono, (2012), Statistika Untuk Penelitian, CV Alfabeta, Bandung.

Tjiptono, Fandy, (2012), Service Management Mewujudkan Layanan Prima, CV. Andi Offset, Yogyakarta.

Umar, Husen, (2013), Riset Pemasaran Dan perilaku Konsumen, PT. Gramedia Pustaka Utama, Jakarta. 